\title{
PEMBUATAN PUPUK ORGANIK CAIR MENGGUNAKAN TEKNOLOGI KOMPOSTING SEDERHANA
}

\author{
I.G.A. Kasmawan ${ }^{1}$, G.N. Sutapa ${ }^{2}$, dan I.M. Yuliara ${ }^{3}$
}

\begin{abstract}
ABSTRAK
Tanaman dalam pertumbuhan dan perkembangannya memerlukan dua jenis unsur hara, yaitu unsur hara makro dan mikro. Namun demikian, hanya unsur N, P, dan K yang dibutuhkan tanaman dalam jumlah lebih besar. Tujuan dari penelitian ini adalah untuk menyediakan pupuk organik cair sebagai pupuk penyeimbang mengingat semakin melambungnya harga pupuk di pasaran. Penelitian tentang penggunaan teknologi komposting sederhana dalam pembuatan pupuk organik cair dilakukan dengan melibatkan peserta dari kelompok lansia, yang bersifat ringan dan dapat dilakukan sendiri. Komposter yang digunakan berupa galon $25 \mathrm{~L}$ dengan selang penghubung luar. Ujung selang tersebut dibenamkan dalam botol berisi air untuk menjamin keberlangsungan proses pengomposan dalam suasana anaerob. Pembuatan pupuk organik cair menggunakan bahan pokok berupa hijauan $(5 \mathrm{~kg})$ dan limbah ternak $(1 \mathrm{~kg})$, dengan bahan tambahan terasi $(100 \mathrm{~g})$ dan gula merah $(200 \mathrm{~g})$, serta $200 \mathrm{~mL}$ EM4 sebagai bioaktivator. Lima produk pupuk organik cair yang telah berhasil dibuat memiliki kandungan nitrogen $(\mathrm{N})$, fosfor $(\mathrm{P})$, dan kalium $(\mathrm{K})$ tertinggi masingmasing sebesar $0,16 \%, 153,75 \mathrm{mg} / \mathrm{L}$ dan $663,98 \mathrm{mg} / \mathrm{L}$.
\end{abstract}

Kata Kunci: Unsur hara NPK, pupuk organik cair, lansia, metode komposting, komposter

\begin{abstract}
Plants in growth and development require two types of nutrients, namely macro and micro nutrients. However, only N, P, and K elements are needed plants for larger amount. The purpose of this research is to provide liquid organic fertilizer as balancing fertilizer considering the increasing price of fertilizer in the market. Research on the use of simple composting technology in the manufacture of liquid organic fertilizer is done by involving participants from the elderly group, which is light and can be done alone. The composter used is a $25 \mathrm{~L}$ gallon with an outer connecting hose. The end of the hose is immersed in a bottle of water to ensure the sustainability of the composting process in an anaerobic atmosphere. Production of liquid organic fertilizer using main ingredient in the form of foliage $(5 \mathrm{~kg})$ and livestock waste $(1 \mathrm{~kg})$, with additives suchshrimp paste (100 g) and brown sugar $(200 \mathrm{~g})$, and $200 \mathrm{~mL}$ EM4 as bioactivator. Five successful liquid organic fertilizer products have the highest nitrogen $(\mathrm{N})$, phosphorus $(\mathrm{P})$, and potassium $(\mathrm{K})$ content of $0.16 \%, 153,75 \mathrm{mg} / \mathrm{L}$ and $663,98 \mathrm{mg} / \mathrm{L}$, respectively.
\end{abstract}

Keywords: NPK nutrient elements, liquid organic fertilizer, elderly, composting method, composter

1,2,3 Staf Pengajar Jurusan Fisika, F.MIPA, Universitas Udayana, Email: gdeanthakas@yahoo.com 


\section{PENDAhuluan}

Pada dasarnya, tanaman dalam pertumbuhan dan perkembangannya memerlukan dua jenis unsur hara, yaitu unsur hara makro dan mikro. Kedua unsur hara yang diperlukan oleh tanaman tersebut dapat terpenuhi melalui pemupukan yang tepat dan berimbang. Kelebihan maupun kekurangan unsur hara baik mirko maupun makro dapat menyebabkan pertumbuhan tanaman menjadi kurang optimal. Unsur hara makro meliputi nitrogen $(\mathrm{N})$,

fosfor $(\mathrm{P})$, kalium $(\mathrm{K})$, karbon $(\mathrm{C})$, hidrogen $(\mathrm{H})$, oksigen $(\mathrm{O})$, sulfur $(\mathrm{S})$, kalsium $(\mathrm{Ca})$, serta magnesium $(\mathrm{Mg})$ diperlukan tanaman dalam jumlah relatif lebih besar dibandingkan unsur hara mikro, yang meliputi besi $(\mathrm{Fe})$, boron $(\mathrm{B})$, mangan $(\mathrm{Mn})$, tembaga $(\mathrm{Cu})$, seng $(\mathrm{Zn})$, moledinum (Mo), dan klor $(\mathrm{Cl})$. Unsur hara makro yang dibutuhkan oleh tanaman berkisar antara $0,5-3 \%$ dari berat tubuh tanaman, sedangkan unsur hara mikro dibutuhkan dalam jumlah kecil, yaitu beberapa ppm dari berat kering tanaman. Dari keseluruhan unsur makro dan mikro yang harus tersedia bagi tanaman, hanya unsur $\mathrm{N}, \mathrm{P}$, dan $\mathrm{K}$ yang dibutuhkan tanaman dalam jumlah yang lebih besar dibandingkan unsur-unsur lainnya. Oleh karenanya, ketiga unsur tersebut sering disebut unsur hara makro utama (primer) (Sahabat Petani, 2013; Rina, 2015). Salah satu jenis pupuk yang dapat memenuhi kebutuhan unsur hara $\mathrm{N}, \mathrm{P}$, dan $\mathrm{K}$ dan ramah lingkungan adalah pupuk organik cair, yang diperoleh dari proses pengomposan (dekomposisi) bahan-bahan organik di dalam wadah komposter (Hadisuwito, 2007).

Penyediaan pupuk organik penting untuk diupayakan untuk menjaga keseimbangan pemakaian pupuk anorganik dan organik. Beberapa manfaat pupuk organik bagi tanah adalah meningkatkan kesuburan tanah, memperbaiki struktur dan porositas tanah. Selain itu, pupuk organik juga dapat merangsang pertumbuhan mikroorganisme tanah yang menguntungkan, Bagi tanaman, pupuk organik bermanfaat dalam meningkatkan produksi tanaman serta dapat mengendalikan penyakit tanaman. Penggunaan pupuk organik juga aman bagi manusia dan lingkungan (Sentana, 2010 dan Roidah, 2013). Mengingat semakin melambungnya harga pupuk di pasaran, penelitian tentang penggunaan teknologi komposting sederhana dalam pembuatan pupuk organik cair dilakukan dengan melibatkan peserta dari kelompok lansia dalam program Iptek bagi Nasyarakat (IbM) tahun 2017. Pembuatan pupuk tersebut bersifat ringan, menghibur, dan dapat dilakukan sendiri.

\section{METODE PELAKSANAAN}

Setelah sosialisasi program IbM, para peserta kemudian diajak dalam kegiatan praktek pembuatan pupuk. Dalam kegiatan praktek tersebut, peralatan serta bahan-bahan tambahan yang diperlukan para peserta praktek disediakan oleh pelaksana program. Untuk pembuatan pupuk tersebut, beberapa tahapan pelaksanaannya adalah (Rahmah dkk., 2014): (1) Hijauan sebanyak $5 \mathrm{~kg}$ dicincang $1 \mathrm{~cm}$ kemudian dimasukkan ke dalam komposter, (2) Kotoran ternak matang sebanyak 1 kg dimasukkan ke dalam komposter, (3) Terasi dan gula merah masing-masing sebanyak $100 \mathrm{~g}$ dan 200 gr dilarutkan dengan air dan dimasukkan ke dalam komposter, (4) Bakteri (EM4) sebanyak $200 \mathrm{~mL}$ ditambahkan ke dalam komposter, (5) Air sebanyak $4 \mathrm{~L}$ atau secukupnya ditambahkan ke dalam komposter sedemikian hingga diperoleh perbandingan campuran bahan organik dan air sekitar 2:1, (6) Komposter selanjutnya ditutup kencang dan memasukkan ujung selang penghubung dengan botol berisi air. Komposter tersebut kemudian disimpan di tempat sejuk dan teduh. Pengadukan bahan organik dapat dilakukan setelah dua hari pengomposan, (7) Bila pengomposan telah berlangsung dengan sempurna, yang dicirikan seperti bau tape yang sedang masak, pemanenan pupuk dapat dilakukan. Pada umumnya, pupuk tersebut dapat dipanen setelah 12 hari pengomposan. Lamanya waktu panen sangat bergantung kepada jenis bakteri yang digunakan (Setawan, 2009). Dari beberapa sampel pupuk yang telah dihasilkan, diambil lima sampel untuk diperiksa di laboratorium yang telah diakreditasi. Pemeriksaan sampel terbatas pada kandungan hara N, P dan K saja.

VOLUME 17 NOMOR 1, JANUARI 2018 | 104 
Tempat pengomposan bahan organik umumnya disebut sebagai komposter, yang dapat dibuat dari wadah plastik (galon) cukup tebal yang dilengkapi dengan tutup. Alasannya adalah untuk menghindari adanya interaksi bahan organik dengan komposter dan untuk menjamin keberlangsungan proses fermentasi yang dikondisikan dalam suasana anaerob. Komposter tersebut dibuat menggunakan teknologi sederhana, yaitu dengan membuat saluran saluran pembuangan gas hasil fermentasi tanpa adanya udara masuk ke dalam komposter. Tutup komposter dibiarkan tertutup rapat selama proses pengomposan berlangsung. Sebuah pipa/selang plastik penghubung dipasang rapat pada tutup komposter dan ujung lainnya dicelupkan pada botol berisi air sekitar $2 / 3$ bagian. Pengisian bahan organik dan pemanenan produk jadi (pupuk cair) dilakukan hanya melalui tutup komposter. Produk hasil pengomposan bahan organik dengan komposter dapat dipanen setelah 12 hari dengan metode penyaringan. Produk pupuk organik cair kemudian dikemas dalam botol plastik dan disimpan di tempat aman dan sejuk (Priyowidodo, 2017).

\section{HASIL DAN PEMBAHASAN}

Sosialisasi pembuatan pupuk organik cair diikuti peserta program sebanyak 15 orang yang diambil dari para pensiunan baik dari negeri maupun swasta, di mana $75 \%$ di antaranya adalah pensiunan PNS. Dalam Gambar 3.1 terlihat suasana sosialisasi tersebut yang kemudian diakhiri dengan demonstrasi penggunaan komposter untuk pembuatan pupuk organik cair.

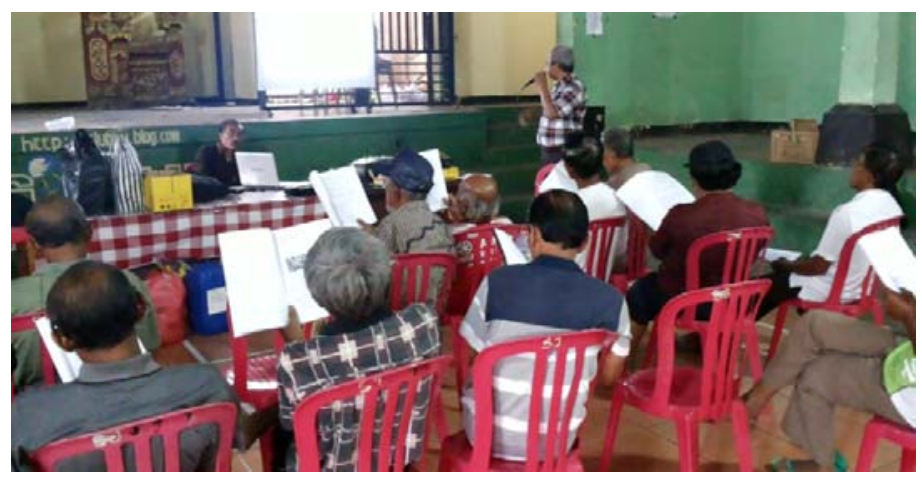

Gambar 3.1. Sosialisasi Pembuatan Pupuk Organik Menggunakan Komposter Sederhana

Setelah praktek pembuatan pupuk organik cair dilakukan secara bersama-sama, para peserta diajak untuk membuat pupuk tesebut secara mandiri di rumah masing-masing. Bahan-bahan yang digunakan berupa: campuran hijauan yang telah dicincang $1 \mathrm{~cm}$ sebanyak $5 \mathrm{~kg}$, kotoran ternak yang sudah matang (bau tanah) sebanyak $1 \mathrm{~kg}$, terasi udang sebanyak $100 \mathrm{~g}$, gula aren/merah sebanyak 200 g, larutan EM4 sebanyak 200 mL, air bebas kaporit sebanyak $20 \mathrm{~L}$.

Kepada para peserta, jenis bahan-bahan pokok pupuk (hijauan dan limbah kotoran ternak) yang digunakan dibebaskan dan ditimbang sesuai ketentuan. Bahan-bahan tambahan lainnya, seperti terasi, gula merah, dan EM4 diberikan oleh pelaksana program dari sumber yang sama dan ukuran bobotnya ditetapkan seperti ketentuan. Prosedur pembuatan pupuk organik cair seluruhnya menggunakan teknologi komposting sederhana menggunakan komposter yang berupa galon plastik tebal bekas berukuran 25 liter lengkap dengan selang penghubung luar untuk menjamin keberlangsungan proses fementasi anaerob. Pengambilan produk pupuk dari komposter dilakukan setelah 2 minggu proses pengomposan. Langkah-langkah pembuatan pupuk organik cair oleh salah satu peserta atas nama I Wayan Suarta (78 tahun), mantan guru SD, ditunjukkan dalam Gambar 3.2 . 


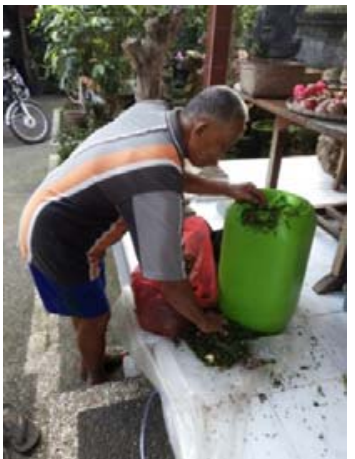

(a)

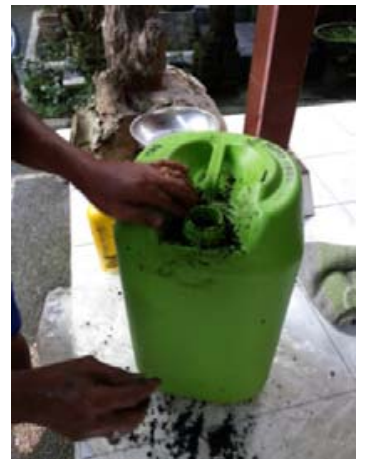

(b)

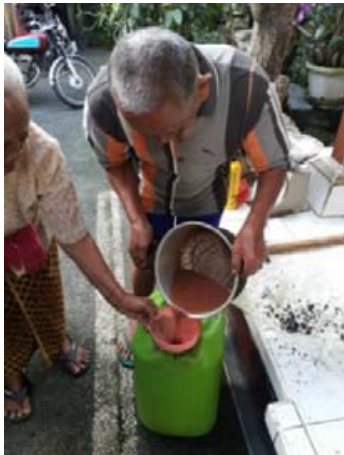

(c)

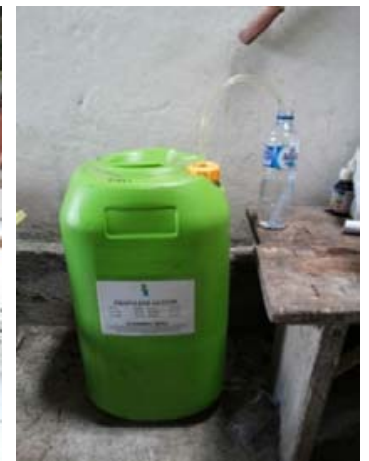

(d)

Gambar 3.2. Proses pembuatan pupuk organik cair menggunakan teknologi komposting sederhana (a) Pemasukan bahan, (b) Pemasukan limbahkotoran ternak, (c) Pemasukan larutan terasi, gula merah, dan EM4 (d) Penempatan komposter di tempat teduh dengan pemasangan selang penghubung komposter.

Sampel pupuk yang telah berhasil diproduksi kemudian diambil sebanyak lima botol untuk diuji di Laboratorium Analitik Universitas Udayana. Bahan-bahan pokok pupuk, yaitu hijauan dan kotoran ternak, yang digunakan untuk pembuatan pupuk organik dan hasil analisa kandungan unsur hara makronya disajikan dalam Tabel 1. Hasil pengujian pupuk tersebut hanya terbatas pada uji kandungan hara makro nitrogen $(\mathrm{N})$, fosfor $(\mathrm{P})$, dan kalium $(\mathrm{K})$.

Tabel 3.1. Bahan Pokok (Hijauan dan Kotoran Ternak) dan Hasil Analisa Pupuk Organik Cair

\begin{tabular}{|c|c|l|l|c|c|c|}
\hline \multirow{2}{*}{ No } & \multirow{2}{*}{$\begin{array}{c}\text { Kode } \\
\text { Pupuk }\end{array}$} & \multicolumn{2}{|c|}{ Bahan Pokok Pupuk } & \multicolumn{3}{c|}{ Kode Pupuk Organik Cair } \\
\cline { 3 - 7 } & A (PC1) & Bayam dan kangkung & Limbah Ternak & N (\%) & P (mg/L) & K (mg/L) \\
\hline 1 & B (PC2) & Daun gamal, pandan, bunga & Kotoran babi & 0,04 & 146.7 & 296,4 \\
\hline 3 & C (PW) & Kulit pisang & Kotoran sapi & 0,07 & 153,75 & 246,48 \\
\hline 4 & D (PD) & Rumput liar dan tebu & Kotoran sapi & 0,06 & 112,31 & 556,47 \\
\hline 5 & E (PTI) & Daun gamal & Kotoran sapi & 0,16 & 117,41 & 663,98 \\
\hline
\end{tabular}

Berdasarkan Tabel 1, Kandungan N pupuk tertinggi sebesar 0,16 \% diperoleh dari campuran daun gamal dan kotoran sapi, kandungan P tertinggi sebesar $153,75 \mathrm{mg} / \mathrm{L}$ diperoleh dari campuran daun gamal, pandan, bunga rampai/sesaji dan kotoran babi, dan kandungan $\mathrm{K}$ tertinggi sebesar 663,98 $\mathrm{mg} / \mathrm{L}$ diperoleh dari campuran rumput liar dan cincangan tebu, dan kotoran sapi. Bila dihitung dalam persen, kandungan $\mathrm{P}$ dan $\mathrm{K}$ tertinggi masing-masing sebesar 0,02 dan 0,07 \%. Hasil analisa NPK pupuk tersebut secara keseluruhan memang belum bisa memenuhi standar pupuk yang telah ditetapkan oleh Peraturan Menteri Pertanian No. 70 tahun 2011 yaitu sebesar 3-6 \%, yang dinilai oleh banyak kalangan bahwa penetapan angka tersebut sangat sulit terpenuhi. Bagaimanapun, produk pupuk organik yang telah berhasil diproduksi oleh peserta program dapat diaplikasikan pada tanaman dengan atau tanpa pupuk anorganik. Kandungan hara produk pupuk organik cair masih dapat ditingkatkan dengan memvariasi bahan-bahan organik yang digunakan berdasarkan pada hasil uji lab yang telah diperoleh. Untuk meningkatkan unsur nitrogen, perlu ditambahkan bahan organik berupa pupuk kandang dan tanaman legum (kacang-kacangan), untuk fosfor ditambahkan cacahan pisang atau batang pisang, sedangkan untuk kalium ditambahkan campuran bahan organik berupa batang pisang, kulit kentang, atau rumput laut.

\section{SIMPULAN DAN SARAN}

Berdasarkan uraian sebelumnya dapat disimpulkan bahwa pembuatan pupuk organik cair dapat dibuat menggunakan metode komposting sederhana. Komposter yang digunakan berupa galon $25 \mathrm{~L}$ 
dengan selang penghubung luar yang ujungnya dibenamkan dalam botol berisi air untuk menjamin keberlangsungan proses pengomposan dalam suasana anaerob. Produk pupuk organik cair yang dihasilkan memiliki kandungan hara makro yang beragam yang sangat tergantung pada campuran bahan organik pupuk yang digunakan. Lima produk pupuk yang telah berhasil diproduksi dengan bahan baku hijauan dan kotoran ternak dengan bahan tambahan terasi dan gula merah serta EM4. Produk pupuk tersebut memiliki kandungan NPK tertinggi masing-masing sebesar 0,16 \%, 153,75 $\mathrm{mg} / \mathrm{L}$ dan $663,98 \mathrm{mg} / \mathrm{L}$.

Langkah perbaikan agar kandungan pupuk dapat ditingkatkan perlu kegiatan praktek yang lebih banyak lagi. Peningkatan kandungan unsur hara pupuk organik cair ditingkatkan melalui penambahan variasi campuran bahan organik yang beragam.

\section{UCAPAN TERIMAKASIH}

Kami mengucapkan terima kasih kepada Kemenristekdikti melalui LPPM Universitas Udayana yang telah mendanai Hibah Pengabdian: Iptek bagi Masyarakat (IbM) Tahun 2017. Kami juga berterimakasih kepada semua pihak khususnya kelompok lansia Desa Jegu, Penebel, Tabanan yang telah aktif berpartisipasi selama kegiatan berlangsung.

\section{DAFTAR PUSTAKA}

Hadisuwito, S. 2007. Membuat Pupuk Kompos Cair. Redaksi AgroMedia Pustaka. Jakarta. ISSBN 979006116-1

Priyowidodo, T. 2017. Cara Membuat Pupuk Organik Cair. http://alamtani.com/pupuk- organik-cair.html. diakses tanggal 18 Februari 2017.

Rahmah, A.; Izzati, M., Parman, S. 2014. Pengaruh Pupuk Organik Cair Berbahan Dasar Limbah Sawi Puth (Brassica chinensis l.) terhadap Pertumbuhan Tanaman Jagung Manis (Zea mays l. Var. Saccharata). Buletin Anatomi dan Fisiologi Volume XXII, No.1.

Rina D. 2015. Manfaat Unsur N, P, dan K bagi Tanaman. BPTP Kaltim (Balai Pengkajian Teknologi Pertanian Kalimantan Timur) diakses Tanggal 16 Oktober 2017. http://kaltim.litbang.pertanian.go.id/ind/index.php?option=com_content\&view=article\&id=707:manfaatunsur-n-p-dan-k-bagi-tanaman\&catid=26:lain\&Itemid $=59$

Roidah, I. A. 2013. Manfaat Penggunaan Pupuk Organik untuk Kesuburan Tanah. Jurnal Universitas Tulungagung Bonorowo Vol. 1.No.1

Sentana, S. 2010. Pupuk Organik, Peluang dan Kendalanya Prosiding Seminar Nasional Teknik Kimia "Kejuangan" Pengembangan Teknologi Kimia untuk Pengolahan Sumber Daya Alam Indonesia Yogyakarta. ISSN 1693-4393

Setawan, E. 2009. Pengaruh Empat Macam Pupuk Organik terhadap Pertumbuhan Sawi. Embryo Vol. 6 No.1. ISSN 0216-0188. 